\title{
Demographics as determinants for predicting quality of life among senior citizens in the Philippines
}

Palmes, Madonna S.

College of Nursing, West Visayas State University, Iloilo City, Philippines (madonna.palmes@wvsu.edu.ph Trajera, Sheilla M.

Center for Linkages and International Affairs, BSN, MN, and PhD Programs in Nursing, University of St. La Salle, Bacolod City, Philippines (s.trajera@usls.edu.ph)

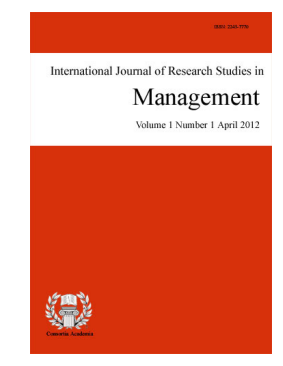

ISSN: 2243-7770 Online ISSN: 2243-7789

Ching, Gregory S.

OPEN ACCESS

Graduate Institute of Educational Leadership and Development,

Research and Development Center for Physical Education Health and Information Technology,

Fu Jen Catholic University, Taiwan (gregory_ching@yahoo.com)

Received: 2 August $2021 \quad$ Revised: 20 September $2021 \quad$ Accepted: 27 September 2021 Available Online: 28 September $2021 \quad$ DOI: $10.5861 /$ ijrsm.2021.m101

\section{Abstract}

Socioeconomic status and education of an individual are said to be highly-related to future quality of life. Within the Philippines, the 2018 statistics have reported that the number of families living below the poverty line is around $11.90 \%$. Although this figure is already a large improvement from the 2015 census of $18.40 \%$. However, due to COVID-19, the situation today might be altogether different. A total of 392 volunteer senior citizen participated in the study, wherein demographics such as: age, gender, marital status, average monthly income, educational attainment, and health status are collected. In addition, senior citizens' resilience, coping strategies, and quality of life are also collected. Data analysis involved Chi-square test for independence, correlational analysis, and linear regression. Findings showed that resilience, coping strategies, social participation, and quality of life are not related to gender and marital status, while average monthly income and educational attainment are related to resilience and cognitive coping strategies. Regression results showed that resilience and social participation both successfully predicted the quality of life for the current group of senior citizens.

Keywords: quality of life, senior citizens, Philippines, survey method, group differences 


\section{Demographics as determinants for predicting quality of life among senior citizens in the Philippines}

\section{Introduction}

Studies have long shown that an individual's quality of life (QOL) is highly related to their educational attainment (Edgerton et al., 2012). In the Philippines, one of the perennial problem of low income families is the significant negative effect of poverty has on student enrollment and completion rates (Alampay \& Garcia, 2019). This actually translate to the lowering of the QOL among low income families (Bérenger \& Verdier-Chouchane, 2007). Within the Philippines, the 2018 government statistics have reported that the number of families living below the poverty line is around $11.90 \%$ (Philippine Statistics Authority, 2020). This would mean that around one in every ten families are having difficulty in surviving. Although this figure is already a large improvement from the 2015 census of $18.40 \%$. Nonetheless, the COVID-19 pandemic has surely make the situation much worst today.

Understanding the aging population, their common aging physical challenges, and how the senior citizens cope are vital in ensuring a future of competent nursing care. With the increasing number of the senior citizens' population, nurses are expected to take care of more and more older people. In essence, nurses and their roles are able to impact future QOL in terms of better care of the older persons, both in the hospital and within the community setting. As senior citizens advance in age, acute and chronic health conditions are more frequently experienced by these vulnerable group, hence it would be insightful to better understand the predictors of future QOL. To date, resilience, coping strategies, and social participation are concepts that are gaining attention in gerontology research. In light of these issues, the current study shall focus on these factors as predictors of QOL among senior citizens in the Philippines. More specific research goal is to determine the levels of resilience, coping strategies, social participation, and QOL of the select senior citizens and compare them to their sociodemographic profile.

\subsection{The aging population and $Q O L$}

The population of the world today is graying quickly (Wang, 2020). This pattern of aging is actually expected to continue and expand all throughout the world. Aging is a universal population characteristic of the current 21st century, resulting from the increased survival rates and improved health care systems. Statistics show that there has been a firm increase among elderly population from 205 million in 1950 to 810 million in 2012, and this number is projected to soar up to two billion by 2050 (Fernandez-Viadero et al., 2018). Nationally and internationally, understanding the lifecycle contributors to aging is crucial as people are experiencing a gerontological explosion of adults. It is noteworthy, that individuals are now demonstrating healthy active lifestyle and tends to live longer. However, in aging, the incidence of disease is slowly taking place, but due to scientific evolution, it is more likely to be managed with improved healthcare and access to services (McMaughan et al., 2020). Nonetheless, people must remain attentive in recognizing that inequalities exist and accept that not everyone has access to affordable health care and other health services (Johar et al., 2018). Hence, improvement of the aging population's well-being is a very critical social issue that needs to be addressed by everyone.

As mentioned previously, the number of senior citizens or senior citizens in the Philippines is also growing. As the population ages, there is also an increasing demand in terms of health care services. It is undeniable that older people starts to have a health decline, particularly degenerative and chronic diseases that start to affect them due to aging of the body's immune system (Faner \& Chiong, 2020). Furthermore, many older people also struggle with poverty, which inevitably affects their QOL. In sum, the senior citizens are a population group that needs an explicit and vital method in promoting health and well-being. 


\subsection{Factors associated with $Q O L$}

Noting that the physical, psychological, emotional, and social capacities of an individual is highly influenced by their age; health related QOL, therefore carries a general sense of well-being containing aspects of happiness and satisfaction of life (Medvedev \& Landhuis, 2018). In a study by Galiana et al. (2016), it was revealed that the worst QOL, which is the lowest among the perceived health, life satisfaction, and social support, are hypothesized among the oldest group of people. As the individuals become very old, this increases their limitations in terms of health, which can be very overwhelming, thus reducing positive emotions. Furthermore, age has been linked to life satisfaction, hence many studies discovered that there is a slight decrease in the life satisfaction among the elderly (Galiana et al., 2016). In addition, findings also revealed that women have been found to have poorer perceived health, but better social relations and QOL than men. Similarly, widows and widowers are posited to have lower average levels of QOL as compared to married elderly. While, educational attainment is hypothesized to improve QOL, including a better perceived health, life satisfaction, and social relations (Galiana et al., 2016).

Within another study, Hajian-Tilaki et al. (2017) showed that QOL is found to be significantly higher in men. The highest score of QOL was observed in the subscale of social functioning, while the lowest score is found in general health. More specifically, the age group of 60-69 senior citizens scored significantly higher in the overall health related QOL than those in the older age group, while those with higher educational level scored higher than those with lower educational level in their health related QOL. Older adult participants who were married showed significantly higher scores of QOL than others in either of gender. Moreover, among those senior citizens who live alone or who have no partner scored poorer in QOL. Seemingly, these findings suggest that QOL is higher related to an individual's educational attainment, marital status, gender, and age.

As noted, being married is positively associated with the level of QOL in the subscales of physical function, social functioning, vitality, and mental health (Hajian-Tilaki et al., 2017). Similarly, Atal and Cheng (2016) noted that coping abilities matters regardless of the levels of socioeconomic status (SES). On the contrary, a study accomplished in the Philippines reported that SES seems to affect ones QOL (Badana \& Andel, 2018). It is particularly noteworthy that among the participants who had higher coping flexibility, wherein the group with low SES and high stress levels and the group with high SES and low stress levels, tended to report comparable levels of health related QOL (Atal \& Cheng, 2016). Thus, affirming that coping strategies is paramount for better QOL than an individuals' SES.

Another concept that is gaining attention within QOL in senior citizens studies is highly related to an individuals' resilience (Hildon et al., 2010). Resilience is a frequently studied concept in conjunction with successful aging, which is a significant concept for senior citizens who wish to age in place (or simply to have a better QOL) (Martin et al., 2015). Several studies revealed that senior citizens' resilience does not diminished with age (Lau et al., 2018), while taking other aspects into consideration, they are as resilient as younger adults. On the other hand, varying results have been found involving men to be more resilient in older age, while some showed that women are better in aging. The level of resilience in older individual may be associated with the level of overall health and well-being, hence for those individuals with a greater feeling of health and well-being; they are supposed to be more resilient (MacLeod et al., 2016). MacLeod et al. (2016) further demonstrated that increasing age is associated with higher levels of resilience, which explains that younger adults may not be as resilient as those who are senior citizens. Hence, those who are more likely to age successfully are known to be highly resilient.

Within another spectrum, it was reported that women are more capable at developing and maintaining social relations than men (Alsubaie et al., 2019). Nonetheless, social relations are crucial for the improvement of QOL (Kim \& Lee, 2018). For instance, involvement in communities such as volunteering were observed among older women, which probably resulted in improved resilience (MacLeod et al., 2016). Such interactions are considered as social participation. Social participation changes when people reach a certain age, this is believed to be 
common within our life cycle transitions (e.g., retirement, change of roles), which changes overtime; more important, this change is also related to the deteriorating physical and cognitive health capacities of an individual (Aroogh \& Shahboulaghi, 2020). Therefore, social participation can be recognized as a vital approach for nurturing empowerment and commitment, which is seen as predominantly valuable for senior citizens; more often they are associated with a series of well-being and QOL indicators.

Social participation plays a very vital role in the mental health of the senior citizens (Takagi et al., 2013), enhancing life contentment and subsequently, improving the QOL (Tobin et al., 2014). According to the theory of activity for successful aging, in order to preserve old roles, one must have new roles to be discovered or new things must be innovated (Katz, 2000). QOL for senior citizens highlights social procedures and alteration of social aims for establishment of a dynamic life, it can be attained through social support and social engagement. Hence, social participation is one of the effective elements within an individual's overall health, which helps facilitates later QOL.

\title{
2. Framework of the study
}

This study is anchored within the Resilience Theory (Southwick et al., 2014) and the Roy's Adaptation Model (RAM) (Roy, 1970, 1971). The Resilience Theory describes resilience as a developmental and dynamic process that originates in childhood and continues until the end of life (Masten \& Barnes, 2018). It is actually the individual's capacity to protect, adapt, and persevere (Reivich \& Shatté, 2002); more specifically, the ability to define the outcome of whether or not they can overcome adverse threats and function effectively (Southwick et al., 2014). RAM (Roy, 1970, 1971), which is highly related to the seminal concepts of Bertalanffy's (Bertalanffy, 1972) systems theory (includes the views on holism, interdependence, control processes, information feedback, and complexity) and Helson's (Helson, 1964) adaptation-level theory (human behavior is adaptive, levels of adaptation differ according to circumstances); noted that each individual has a specific adaptive level. Furthermore, coping mechanisms or strategies of individuals are factors that could influence this adaptive level. Within RAM, two distinct subsystems of coping mechanisms are mentioned: A) Regulatory subsystem, which is composed of elements such as the input, processing and output. It is the individual's basic mechanism of coping with stimuli. The regulator responds to external and internal stimuli mainly by neural, chemical, and endocrine responses. B) Cognatory subsystem, which is associated with the higher nervous activity. It reacts to the external and internal stimuli mainly by these responses: emotions, learning, solving of problems, attention and memory, and decision making (Andrews \& Roy, 1986; Roy, 1970, 1971). In essence, RAM can be considered as a theory-based intervention that is both holistic and dynamic. Dynamic in a sense that the mechanisms changes as it interacts with the environment.

Methodology - In order to best describe the various predictors of QOL and at the same time understand the relationship that exists between them. The current study utilized the descriptive quantitative research paradigm, wherein data are collected using a survey questionnaire. In addition, the data collected is also used to describe the characteristics of the current phenomenon in focus (Cohen et al., 2007). Besides the relevant participants' sociodemographic background such as age, gender, educational attainment, marital status, SES or average monthly family income, health status, and community participation (Weisberg et al., 1996), several validated instruments are also utilized, such as resilience, coping strategies, social participation, and the QOL scale.

\section{Results and discussion}

\author{
3.1 Participants' levels of resilience, coping strategies, social participation, and QOL as compared to their \\ sociodemographic profile
}

Computation for the participants' levels of resilience, coping strategies, social participation, and QOL were accomplished. In addition, classification of the different levels or interpretation of the scales are all based on the 
corresponding instructions provided. Table 1 shows the summary of the various results with their corresponding classification. As a whole, the participants' resilience level can be considered as moderately high with a mean score of 82.55. While the average of the two coping strategies is 60.27 with behavioral strategies (61.28) slightly higher than the cognitive ones (59.95). Furthermore, social participation is computed at 35.68, signifying good social participations among the senior citizens. Lastly, QOL among the participants is computed at 128.91, denoting high QOL.

\section{Table 1}

Participants' level of resilience, coping strategies, social participation, and $Q O L$

\begin{tabular}{|c|c|c|c|c|c|c|}
\hline Category & Classification & & $n$ & $\%$ & Mean & $S D$ \\
\hline \multirow[t]{7}{*}{ Resilience } & Very low (14-56) & & 0 & 0.0 & 0.00 & 0.00 \\
\hline & Low $(57-64)$ & & 31 & 7.9 & 60.61 & 2.46 \\
\hline & On the low end (65-73) & & 78 & 19.9 & 69.03 & 2.46 \\
\hline & Moderate (74-81) & & 53 & 13.5 & 77.70 & 2.17 \\
\hline & Moderately high (82-90) & & 94 & 24.0 & 85.98 & 2.28 \\
\hline & High $(91-98)$ & & 136 & 34.7 & 94.82 & 2.47 \\
\hline & & Total & 392 & 100.0 & 82.55 & 11.77 \\
\hline \multirow[t]{3}{*}{ Coping Strategies } & Cognitive & & 298 & 76.0 & 59.95 & 7.22 \\
\hline & Behavioral & & 94 & 24.0 & 61.28 & 14.82 \\
\hline & & Total & 392 & 100.0 & 60.27 & 9.60 \\
\hline \multirow[t]{5}{*}{ Social Participation } & Poor (1-12) & & 0 & 0.0 & 0.00 & 0.00 \\
\hline & Fair (13-24) & & 17 & 4.3 & 20.24 & 3.51 \\
\hline & Good (26-36) & & 215 & 54.8 & 32.38 & 2.93 \\
\hline & Excellent (37-48) & & 160 & 40.8 & 41.76 & 3.78 \\
\hline & & Total & 392 & 100.0 & 35.68 & 6.52 \\
\hline \multirow[t]{4}{*}{ QOL } & Low $(35-58)$ & & 0 & 0.0 & 0.00 & 0.00 \\
\hline & Moderate (59-116) & & 27 & 6.9 & 107.52 & 7.73 \\
\hline & High (117-175) & & 365 & 93.1 & 130.49 & 7.49 \\
\hline & & Total & 392 & 100.0 & 128.91 & 9.49 \\
\hline
\end{tabular}

Note. $N=392$.

Resilience Scale - To better understand the relationship between the participants' level of resilience and sociodemographic profile, several cross-tabulations and Chi-square test of differences were accomplished. Findings show that there seems to be no significant differences between the participants' level of resilience and their age group, gender, marital, and health status. However, significant differences were found with respect to the participants' educational attainment and SES (average monthly family income).

Table 2 shows the distribution of the level of resilience of participants by educational attainment. A Chi-square test of independence was performed to examine the relationship between the level of resilience and educational attainment. Findings show that there were significant differences between the two with $\chi^{2}(12, N=$ $392)=34.92, p<0.001$. Most of the participants who graduated in college (68 or $42.8 \%$ ) seems to be more resilient as compared to those participants who graduated in high school (37 or 32.5\%) and in the elementary (22 or $23.7 \%$ ). It can be inferred that participants who had higher educational level tended to report higher resilience as compared to those who have lower educational level. This can be explained that senior citizens with high education have more capacity to adapt to life's challenges, this might be due to their increase capability of using coping strategies and social connection, which would even demonstrate to better financial resources that promotes resilience (Hassani et al., 2017).

Table 3 shows the distribution of the participants' level of resilience by SES in terms of average monthly family income. A Chi-square test of independence was performed to examine the relationship between the level of resilience and SES. Findings show that there were significant differences between the two with $\chi^{2}(8, N=$ $392)=30.67, p<0.001$. It would seem that participants who had moderate SES (66 or 35.3\%) and high SES (45 or $39.8 \%$ ) were more resilient than those participants whose reported income belonging to low SES (25 or 27.2\%). Hassani et al. (2017) further noted that senior citizens with average or good socioeconomic standing are 
Palmes, M. S., Trajera, S. M., \& Ching, G. S.

able to provide better access to services that facilitate participation to social activities; hence creating better social connection, which contributes to increased resiliency of the individual.

Table 2

Level of resilience of participants by educational attainment

\begin{tabular}{|c|c|c|c|c|c|c|c|c|c|c|}
\hline \multirow{3}{*}{ Level of Resilience } & \multicolumn{8}{|c|}{ Educational Attainment } & \multirow{2}{*}{\multicolumn{2}{|c|}{ Total }} \\
\hline & \multicolumn{2}{|c|}{ Elementary } & \multicolumn{2}{|c|}{ High School } & \multicolumn{2}{|c|}{ College } & \multicolumn{2}{|c|}{ Graduate } & & \\
\hline & $n$ & $\%$ & $n$ & $\%$ & $n$ & $\%$ & $n$ & $\%$ & $n$ & $\%$ \\
\hline Very low (14-56) & 0 & 0.0 & 0 & 0.0 & 0 & 0.0 & 0 & 0.0 & 0 & 0.0 \\
\hline Low $(57-64)$ & 12 & 12.9 & 7 & 6.1 & 11 & 6.9 & 1 & 3.8 & 31 & 7.9 \\
\hline On the low end (65-73) & 32 & 34.4 & 27 & 23.7 & 15 & 9.4 & 4 & 15.4 & 78 & 19.9 \\
\hline Moderate (74-81) & 10 & 10.8 & 13 & 11.4 & 24 & 15.1 & 6 & 23.1 & 53 & 13.5 \\
\hline Moderately high (82-90) & 17 & 18.3 & 30 & 26.3 & 41 & 25.8 & 6 & 23.1 & 94 & 24.0 \\
\hline High (91-98) & 22 & 23.7 & 37 & 32.5 & 68 & 42.8 & 9 & 34.6 & 136 & 34.7 \\
\hline Total & 93 & 100.0 & 114 & 100.0 & 159 & 100.0 & 26 & 100.0 & 392 & 100.0 \\
\hline
\end{tabular}

Table 3

Level of resilience of participants by average monthly family income

\begin{tabular}{|c|c|c|c|c|c|c|c|c|}
\hline \multirow{3}{*}{ Level of Resilience } & \multicolumn{6}{|c|}{ Average Monthly Family Income ${ }^{1}$} & \multirow{2}{*}{\multicolumn{2}{|c|}{ Total }} \\
\hline & \multicolumn{2}{|c|}{ Below 5,000 } & \multicolumn{2}{|c|}{$5,000-15,000$} & \multicolumn{2}{|c|}{ Above 15,000} & & \\
\hline & $n$ & $\%$ & $n$ & $\%$ & $n$ & $\%$ & $n$ & $\%$ \\
\hline Very low (14-56) & 0 & 0.0 & 0 & 0.0 & 0 & 0.0 & 0 & 0.0 \\
\hline Low $(57-64)$ & 3 & 3.3 & 19 & 10.2 & 9 & 8.0 & 31 & 7.9 \\
\hline On the low end (65-73) & 36 & 39.1 & 25 & 13.4 & 17 & 15.0 & 78 & 19.9 \\
\hline Moderate (74-81) & 9 & 9.8 & 28 & 15.0 & 16 & 14.2 & 53 & 13.5 \\
\hline Moderately high (82-90) & 19 & 20.7 & 49 & 26.2 & 26 & 23.0 & 94 & 24.0 \\
\hline High $(91-98)$ & 25 & 27.2 & 66 & 35.3 & 45 & 39.8 & 136 & 34.7 \\
\hline Total & 92 & 100.0 & 187 & 100.0 & 113 & 100.0 & 392 & 100.0 \\
\hline
\end{tabular}

Note. Chi-square $=30.67, \mathrm{df}=8, p<0.001$ (Significant relationship).

${ }^{1}$ Monthly average income is in Philippine Peso (PHP); 1 USD $=49$ (PHP).

In the study conducted by Kok et al. (2018), they illustrated that despite low socioeconomic standing, senior citizens revealed a high level of resilience. For the participants having low SES, it is not considered as a hindrance to develop a capacity to bounce back after adversity. Instead, some of them discounted social standing and were actually proud of their modest lives. This finding has provided some insights as to what factors may be considered in preventing diminished health and functioning in senior citizens.

Coping Strategies - For the participants' coping strategies, cross-tabulations and Chi-square test of differences show that there seems to be no significant differences between the participants' age group, gender, marital, and health status. However, significant differences were found with respect to the participants' educational attainment and SES (average monthly family income). Table 4 shows the distribution of participants' coping strategies by educational attainment. A Chi-square test of independence was performed to examine the relationship between the coping strategies and educational attainment. Findings show that there were significant differences between the two with $\chi^{2}(3, N=392)=11.71, p<0.01$.

Table 4 shows the distribution of participants' coping strategies in terms of educational attainment, the majority of the participants who are college graduate (131 or $82.4 \%$ ), high school graduate ( 88 or $77.2 \%$ ), and elementary graduate (59 or $63.4 \%$ ) utilized cognitive coping strategies as compared to behavioral coping strategies. It would seem that senior citizens with higher educational attainment utilized more cognitive coping strategies than behavioral coping strategies. Since, higher educational attainment can be related to greater access to social and material resources, while having fewer adverse experiences over the life course. Therefore, it can be implied that enhanced education is able to provide better ability to maintain psychosocial functioning (Mitchell et al., 2018). 
Demographics as determinants for predicting quality of life among senior citizens in the Philippines

Table 4

Coping strategies of participants by educational attainment

\begin{tabular}{|c|c|c|c|c|c|c|c|c|c|c|}
\hline \multirow{3}{*}{ Coping Strategies } & \multicolumn{8}{|c|}{ Educational Attainment } & \multirow{2}{*}{\multicolumn{2}{|c|}{ Total }} \\
\hline & \multicolumn{2}{|c|}{ Elementary } & \multicolumn{2}{|c|}{ High School } & \multicolumn{2}{|c|}{ College } & \multicolumn{2}{|c|}{ Graduate } & & \\
\hline & $n$ & $\%$ & $n$ & $\%$ & $n$ & $\%$ & $n$ & $\%$ & $n$ & $\%$ \\
\hline Cognitive & 59 & 63.4 & 88 & 77.2 & 131 & 82.4 & 20 & 76.9 & 298 & 76.0 \\
\hline Behavioral & 34 & 36.6 & 26 & 22.8 & 28 & 17.6 & 6 & 23.1 & 94 & 24.0 \\
\hline Total & 93 & 100.0 & 114 & 100.0 & 159 & 100.0 & 26 & 100.0 & 392 & 100.0 \\
\hline
\end{tabular}

Note. Chi-square $=11.71, \mathrm{df}=3, p<0.01$ (Significant relationship).

Table 5 shows the distribution of participants' coping strategies by SES in terms of average monthly family income. A Chi-square test of independence was performed to examine the relationship between the coping strategies and SES. Findings show that there were significant differences between the two with $\chi^{2}(2, N=392)$ $=14.15, p<0.01$. Findings also noted that majority of the participants within the three income groups with average SES (154 or $82.4 \%$ ), high SES (87 or $77.0 \%$ ), and low SES (57 or $62.0 \%$ ) utilized more cognitive coping strategies than behavioral coping strategies. It can be inferred that senior citizens with average SES utilized more cognitive coping strategies than behavioral strategies. Roohafza et al. (2009) revealed that senior citizens with increasing SES could increase the utilization of adaptive coping skills such as cognitive coping strategy. Hence, it would seem that financial situation of senior citizens is quite important in fostering adaptive aging skills.

Table 5

Coping strategies of participants by average monthly family income

\begin{tabular}{|c|c|c|c|c|c|c|c|c|}
\hline \multirow{3}{*}{ Coping Strategies } & \multicolumn{6}{|c|}{ Average Monthly Family Income ${ }^{1}$} & \multirow{2}{*}{\multicolumn{2}{|c|}{ Total }} \\
\hline & \multicolumn{2}{|c|}{ Below 5,000 } & \multicolumn{2}{|c|}{$5,000-15,000$} & \multicolumn{2}{|c|}{ Above 15,000} & & \\
\hline & $n$ & $\%$ & $n$ & $\%$ & $n$ & $\%$ & $n$ & $\%$ \\
\hline Cognitive & 57 & 62.0 & 154 & 82.4 & 87 & 77.0 & 298 & 76.0 \\
\hline Behavioral & 35 & 38.0 & 33 & 17.6 & 26 & 23.0 & 94 & 24.0 \\
\hline Total & 92 & 100.0 & 187 & 100.0 & 113 & 100.0 & 392 & 100.0 \\
\hline
\end{tabular}

Note. Chi-square $=14.15, \mathrm{df}=2, p<0.01$ (Significant relationship).

${ }^{1}$ Monthly average income is in Philippine Peso (PHP); 1 USD $=49$ (PHP).

Social Participation - For the participants' social participation, cross-tabulations and Chi-square test of differences show that there seems to be no significant differences between the participants' gender, educational attainment, SES (average monthly family income), and marital status. However, significant differences were found with respect to the participants' age group and health status. Table 6 shows the distribution of social participation level of participants by age group. A Chi-square test of independence was performed to examine the relationship between the level of social participation and age group. Findings show that there were significant differences between the two with $\chi^{2}(4, N=392)=19.28, p<0.01$.

Among the age group, Table 6 shows that a little more than half of the participants 70-79 years old (61 or $52.1 \%$ ) had excellent social participation, while half of the age group 60-69 years old (142 or 58.9\%) had good social participation, and 21 or $61.8 \%$ of the age group 80 and above had good social participation. Pinto et al. (2017) reported that younger senior citizens enjoy better health conditions after retirement. They have reported to have more time to devote in social life. However, as they advance in age, they experience more challenges particularly within health and economic problems, which eventually hindered their social activities. In addition to, as age increases, there is also an increasing health restrictions, thus creating a change in social participation. It is noteworthy to observe that younger and healthier senior citizens were more participative in social activities (Bukov et al., 2002).

Table 7 shows the distribution of the level of social participation of participants in terms of health status. A Chi-square test of independence was performed to examine the relationship between the level of social participation and health status or the number of self-reported chronic diseases. Findings show that there were 
Palmes, M. S., Trajera, S. M., \& Ching, G. S.

significant differences between the two with $\chi^{2}(8, N=392)=20.37, p<0.01$. Findings show that half of the participants who reported with no chronic disease (60 or 50.0\%) and 9 out of the 18 participants diagnosed with at least four chronic diseases ( 9 or $50.0 \%$ ) were found to have excellent social participation.

Table 6

Level of social participation of participants by age group

\begin{tabular}{|c|c|c|c|c|c|c|c|c|}
\hline \multirow{3}{*}{$\begin{array}{c}\text { Level of } \\
\text { Social Participation }\end{array}$} & \multicolumn{6}{|c|}{ Age } & \multirow{2}{*}{\multicolumn{2}{|c|}{ Total }} \\
\hline & \multicolumn{2}{|c|}{$60-69$} & \multicolumn{2}{|c|}{$70-79$} & \multicolumn{2}{|c|}{$80 \&$ above } & & \\
\hline & $n$ & $\%$ & $n$ & $\%$ & $n$ & $\%$ & $n$ & $\%$ \\
\hline Poor (1-12) & 0 & 0.0 & 0 & 0.0 & 0 & 0.0 & 0 & 0.0 \\
\hline Fair (13-24) & 8 & 3.3 & 4 & 3.4 & 5 & 14.7 & 17 & 4.3 \\
\hline Good (26-36) & 142 & 58.9 & 52 & 44.4 & 21 & 61.8 & 215 & 54.8 \\
\hline Excellent $(37-48)$ & 91 & 37.8 & 61 & 52.1 & 8 & 23.5 & 160 & 40.8 \\
\hline Total & 241 & 100.0 & 117 & 100.0 & 34 & 100.0 & 392 & 100.0 \\
\hline
\end{tabular}

Note. Chi-square $=19.28, \mathrm{df}=4, p<0.01$ (Significant relationship).

Table 7

Level of social participation of participants by health status

\begin{tabular}{|c|c|c|c|c|c|c|c|c|c|c|c|c|}
\hline \multirow{3}{*}{$\begin{array}{l}\text { Level of } \\
\text { Social Participation }\end{array}$} & \multicolumn{10}{|c|}{ Health Status ${ }^{1}$} & \multirow{2}{*}{\multicolumn{2}{|c|}{ Total }} \\
\hline & \multicolumn{2}{|c|}{0} & \multicolumn{2}{|c|}{1} & \multicolumn{2}{|c|}{2} & \multicolumn{2}{|c|}{3} & \multicolumn{2}{|c|}{4} & & \\
\hline & $n$ & $\%$ & $n$ & $\%$ & $n$ & $\%$ & $n$ & $\%$ & $n$ & $\%$ & $n$ & $\%$ \\
\hline Poor (1-12) & 0 & 0.0 & 0 & 0.0 & 0 & 0.0 & 0 & 0.0 & 0 & 0.0 & 0 & 0.0 \\
\hline Fair (13-24) & 9 & 7.5 & 5 & 3.0 & 0 & 0.0 & 1 & 2.3 & 2 & 11.1 & 17 & 4.3 \\
\hline Good (26-36) & 51 & 42.5 & 98 & 58.7 & 29 & 65.9 & 30 & 69.8 & 7 & 38.9 & 215 & 54.8 \\
\hline Excellent (37-48) & 60 & 50.0 & 64 & 38.3 & 15 & 34.1 & 12 & 27.9 & 9 & 50.0 & 160 & 40.8 \\
\hline Total & 120 & 100.0 & 167 & 100.0 & 44 & 100.0 & 43 & 100.0 & 18 & 100.0 & 392 & 100.0 \\
\hline
\end{tabular}

Health status was found to be related to social participation within the senior citizens. A study by Gagliardi and Piccinini (2019) reveals that senior citizens engaging in healthy lifestyle can lead to physical fitness and good health. This factor was associated with participation in different activities within the community. Pinto et al. (2017) demonstrated that older persons with health problems, particularly having mobility limitations, affects social participation. In some sense, findings implied that over time, senior citizens tend to give up their social activities as they experience more health challenges.

Quality of Life - Interestingly, no significant differences were found between the participants' QOL and sociodemographic background. Some implications might be that most senior citizens in Philippines are taken cared by their children. This strong support system provides a strong foundation of QOL. In other words, QOL for the senior citizens in Philippines are most likely not affected by their sociodemographic background. This finding would merit further investigation.

\subsection{Predictors of QOL for senior citizens in the Philippines}

For predicting QOL of senior citizens in Philippines, multiple regression results revealed that only two of the factors; social participation and resilience, fit with the model significantly with $F(2,389)=61.34, p=0.000$. $R^{2}$ for the model was 0.240 , and adjusted $R^{2}$ was 0.236 . Table 8 shows the B, Standardized Error (SE), Beta, $t$ values, and significance levels. With regards to the individual relationships between the independent variables and QOL, both social participation and resilience have positive values. Denoting that both of the predictors are positively correlated with QOL, hence the higher the social participation and resilience of the senior citizens, the more likely they will have higher QOL.

It would seem that the results of the study were supported by the literature. Most senior citizens demonstrated high well-being and better QOL despite of the beginning of the onset of chronic health condition. Moreover, senior citizens with positive outlook in life has been associated with high resilience and successful 
aging. Furthermore, research suggests that senior citizens can obtain an improved QOL with high resilience, which includes happiness, better health status, and contentment with life. Therefore, they are more likely to age successfully, thus are more likely to engage in social activities, which are linked to social participation; as one of the predictors of QOL of senior citizens.

In addition, findings also noted that social participation as one of the key predictors of positive and successful aging. Social participation for senior citizens in the Philippines might include activities of daily living, social connections, spirituality, and community life. Maintaining an active and engaging life is important, thus having high levels of social participation is associated with QOL. Enhancing the social participation of senior citizens is a vital factor in successful aging, which translate to high QOL (Douglas et al., 2017).

Table 8

Multiple regressions analysis for $Q O L$

\begin{tabular}{lllllc}
\hline \multicolumn{1}{c}{ Factors } & \multicolumn{1}{c}{ B } & SE & Beta & $t$ & $p$ \\
\hline Constant & 94.75 & 3.35 & & 28.29 & 0.000 \\
Social Participation & 0.57 & 0.07 & 0.39 & 8.44 & 0.000 \\
Resilience & 0.17 & 0.04 & 0.21 & 4.58 & 0.000 \\
\hline
\end{tabular}

\section{Conclusion}

Considering the various concepts and issues mentioned, it is high time that attention is focused on areas relevant to the well-being of the older adult population. Conveying the understanding of this understudied group, the senior citizens in line with their needs and the bearing they will have on society will be an achievable encounter of up-to-date and future generations of researchers. There is significant importance in how senior citizens undertake severe negative life situations, but most of the prior works were mostly dedicated on individuals' responses to one negative event, which has neglected the context wherein these events occur and its influence on the overall coping process. Consequently, there is a limited notion regarding the varied life experiences of the senior citizens and how they deal with challenges among themselves. The different life domains accompanying the chronic stressors that go with it; not to mention the physical and cognitive decline, yet they still manage to bounce back after an adversity. Their resiliency amidst the challenges of aging and the losses they have experienced provided them ample opportunities to experiment on the different ways to cope or to deal with these stressors.

Social participation on the other hand, has a very positive effect in terms of enhancing the QOL of senior citizens. Nowadays, social isolation is a greater risk for an older person, this is because of the various limitations within the dimensions of life for an older adult that hinders his or her social engagement. If social participation is not encouraged among these group, there is a greater risk that most of them will suffer from depression in which eventually could lead to greater morbidity and mortality rates. Social engagement among senior citizens is of the utmost importance, since it provides meaning and has a positive effect on their subjective well-being and towards their overall QOL. In sum, there seems to be a strong positive relationship between resilience, coping strategies, social participation, and QOL. Therefore, more attention should be placed on these domains so as to improve the overall QOL of senior citizens. Lastly, the results could be accomplished or completed with the expansion of other studies that include different methodological designs and analysis.

Acknowledgement: A more complicated statistical computation of the data used in the current study is also available at (Palmes et al., 2021).

\section{References}

Alampay, L. P., \& Garcia, A. S. (2019). Education and parenting in the Philippines. In E. Sorbring \& J. E.

Lansford (Eds.), School systems, parent behavior, and academic achievement (Vol. 3, pp. 79-94).

Springer. https://doi.org/10.1007/978-3-030-28277-6_7 
Palmes, M. S., Trajera, S. M., \& Ching, G. S.

Alsubaie, M. M., Stain, H. J., Webster, L. A. D., \& Wadman, R. (2019). The role of sources of social support on depression and quality of life for university students. International Journal of Adolescence and Youth, 24(4), 484-496. https://doi.org/10.1080/02673843.2019.1568887

Andrews, H. A., \& Roy, C. (1986). Essentials of the roy adaptation model. Appleton-Century-Crofts.

Aroogh, M. D., \& Shahboulaghi, F. M. (2020). Social participation of older adults: A concept analysis. International Journal of Community Based Nursing and Midwifery, 8(1), 55-72. https://doi.org/10.30476/IJCBNM.2019.82222.1055

Atal, S., \& Cheng, C. (2016). Socioeconomic health disparities revisited: Coping flexibility enhances health-related quality of life for individuals low in socioeconomic status. Health and Quality of Life Outcomes, 14, 7. https://doi.org/10.1186/s12955-016-0410-1

Bérenger, V., \& Verdier-Chouchane, A. (2007). Multidimensional measures of well-being: Standard of living and quality of life across countries. World Development, 35(7), 1259-1276. https://doi.org/10.1016/j.worlddev.2006.10.011

Badana, A. N. S., \& Andel, R. (2018). Aging in the Philippines. The Gerontologist, 58(2), 212-218. https://doi.org/10.1093/geront/gnx203

Bertalanffy, L. V. (1972). The history and status of general systems theory. Academy of Management Journal, 15(4), 407-426. https://doi.org/10.5465/255139

Bukov, A., Maas, I., \& Lampert, T. (2002). Social participation in very old age: cross-sectional and longitudinal findings from BASE. Berlin aging study. The Journal of Gerontology, Series B, Psychological Sciences and Social Sciences, 57(6), 510-517. https://doi.org/10.1093/geronb/57.6.p510

Cohen, L., Manion, L., \& Morrison, K. (2007). Research method in education (6th ed.). Routledge.

Douglas, H., Georgiou, A., \& Westbrook, J. (2017). Social participation as an indicator of successful aging: An overview of concepts and their associations with health. Australian Health Review, 41(4), 455-462. https://doi.org/10.1071/AH16038

Edgerton, J. D., Roberts, L. W., \& von Below, S. (2012). Education and quality of life. In K. C. Land, A. C. Michalos, \& M. J. Sirgy (Eds.), Handbook of social indicators and quality of life research (pp. 265-296). Springer.

Faner, M. R., \& Chiong, M. A. D. (2020). Clinical profiles and outcomes of the most common inherited metabolic diseases in the Philippines: A review of the National Institutes of Health - Institute of Human Genetics Metabolic Registry. Acta Medica Philippina, 54(3), 236-243. https://doi.org/10.47895/amp.v54i3.1648

Fernandez-Viadero, C., Nawagi, F., Söderberg, M., Berggren, V., Midlöv, P., Ajambo, A., \& Nakasujja, N. (2018). Sociodemographic characteristics and health profile of the elderly seeking health care in Kampala, Uganda. Current Gerontology and Geriatrics Research, 4147509.

Gagliardia, C., \& Piccinini, F. (2019). The use of nature-based activities for the well-being of older people: An integrative literature review. Archives of Gerontology and Geriatrics, 83, 315-327. https://doi.org/10.1016/j.archger.2019.05.012

Galiana, L., Gutiérrez, M., Sancho, P., Francisco, E.-H., \& Tomás, J. M. (2016). Socio-demographic variables and successful aging of the Angolan elderly. Scientifica, 5306756.

104 Consortia Academia Publishing (A Partner of Tourism Educators and Movers of the Philippines) 
Demographics as determinants for predicting quality of life among senior citizens in the Philippines

Hajian-Tilaki, K., Heidari, B., \& Hajian-Tilaki, A. (2017). Are gender differences in health-related quality of life attributable to sociodemographic characteristics and chronic disease conditions in elderly people. International Journal of Preventive Medicine, 8, 95. https://doi.org/10.4103/ijpvm.IJPVM_197_16

Hassani, P., Izadi-Avanji, F.-S., Rakhshan, M., \& Majd, H. A. (2017). A phenomenological study on resilience of the elderly suffering from chronic disease: A qualitative study. Psychology Research and Behavior Management, 10, 59-67. https://doi.org/10.2147/PRBM.S121336

Helson, H. (1964). Current trends and issues in adaptation-level theory. American Psychologist, 19(1), 26-38. https://doi.org/10.1037/h0040013

Hildon, Z., Montgomery, S. M., Blane, D., Wiggins, R. D., \& Netuveli, G. (2010). Examining resilience of quality of life in the face of health-related and psychosocial adversity at older ages: What is "right" about the way we age. Gerontologist, 50(1), 36-47. https://doi.org/10.1093/geront/gnp067

Johar, M., Soewondo, P., Pujisubekti, R., Satrio, H. K., \& Adji, A. (2018). Inequality in access to health care, health insurance and the role of supply factors. Social Science \& Medicine, 213, 134-145. https://doi.org/10.1016/j.socscimed.2018.07.044

Katz, S. (2000). Busy bodies: Activity, aging, and the management of everyday life. Journal of Aging Studies, 14(2), 135-152. https://doi.org/10.1016/S0890-4065(00)80008-0

Kim, Y. B., \& Lee, S.-H. (2018). Effects of the elderly's health statuses, health behavior, and social relations on their health-related quality of life: Focusing on family types. Journal of Korean Academy of Community Health Nursing, 29(3).

Kok, A. A. L., van Nes, F., Deeg, D. J. H., Widdershoven, G., \& Huisman, M. (2018). "Tough times have become good times": Resilience in older adults with a low socioeconomic position. Gerontologist, 58(5), 843-852. https://doi.org/10.1093/geront/gny007

Lau, S. Y. Z., Guerra, R. O., Barbosa, J. F. d. S., \& Phillips, S. P. (2018). Impact of resilience on health in older adults: A cross-sectional analysis from the International Mobility in Aging Study. Geriatric Medicine, 8(11), e023779. https://doi.org/10.1136/bmjopen-2018-023779

MacLeod, S., Musich, S., Hawkins, K., Alsgaard, K., \& Wicker, E. R. (2016). The impact of resilience among older adults. Geriatric Nursing, 37(4), 266-272. https://doi.org/10.1016/j.gerinurse.2016.02.014

Martin, A. S., Palmer, B. W., Rock, D., Gelston, C. V., \& Jeste, D. V. (2015). Associations of self-perceived successful aging in young-old versus old-old adults. International Psychogeriatrics, 27(4). https://doi.org/10.1017/S104161021400221X

Masten, A. S., \& Barnes, A. J. (2018). Resilience in children: Developmental perspectives. Children, 5(7), 98. https://doi.org/10.3390/children5070098

McMaughan, D. J., Oloruntoba, O., \& Smith, M. L. (2020). Socioeconomic status and access to healthcare: Interrelated drivers for healthy aging. Frontiers in Public Health, 8, 231. https://doi.org/10.3389/fpubh.2020.00231

Medvedev, O. N., \& Landhuis, C. E. (2018). Exploring constructs of well-being, happiness and quality of life. PeerJ, 6, e4903. https://doi.org/10.7717/peerj.4903

Mitchell, U. A., Ailshire, J. A., Brown, L. L., Levine, M. E., \& Crimmins, E. M. (2018). Education and psychosocial functioning among older adults: 4-Year change in sense of control and hopelessness. The 
Palmes, M. S., Trajera, S. M., \& Ching, G. S.

Journal of Gerontology, Series B, Psychological Sciences and Social Sciences, 65B(2), 216-226. https://doi.org/10.1093/geronb/gbp101

Palmes, M. S., Trajera, S. M., \& Ching, G. S. (2021). Relationship of coping strategies and quality of life: Parallel and serial mediating role of resilience and social participation among older adults in Western Philippines. International Journal of Environmental Research and Public Health, 18(19), 10006. https://doi.org/10.3390/ijerph181910006

Philippine Statistics Authority. (2020). Special release: Poverty statistics among families in Western Visayas.

Pinto, J. M., \& Neri, A. L. (2017). Trajectories of social participation in old age: A systematic literature review. Revista Brasileira de Geriatria e Gerontologia, 20(2). https://doi.org/10.1590/1981-22562017020.160077

Reivich, K., \& Shatté, A. (2002). The resilience factor: 7 essential skills for overcoming life's inevitable obstacles. Broadway Books.

Roohafza, H., Sadeghi, M., Shirani, S., Bahonar, A., Mackie, M., \& Sarafzadegan, N. (2009). Association of socioeconomic status and life-style factors with coping strategies in Isfahan Healthy Heart Program, Iran. Croatian Medical Journal, 50(4), 380-386. https://doi.org/10.3325/cmj.2009.50.380

Roy, C. (1970). Adaptation: A conceptual framework for nursing. Nursing Outlook, 18, 42-45.

Roy, C. (1971). Adaptation: A basis for nursing practice. Nursing Outlook, 19, 254-257.

Southwick, S. M., Bonanno, G. A., Masten, A. S., Panter-Brick, C., \& Yehuda, R. (2014). Resilience definitions, theory, and challenges: Interdisciplinary perspectives. European Journal of Psychotraumatology, 5(1). https://doi.org/10.3402/ejpt.v5.25338

Takagi, D., Kondo, K., \& Kawachi, I. (2013). Social participation and mental health: Moderating effects of gender, social role and rurality. BMC Public Health, 13, 701. https://doi.org/10.1186/1471-2458-13-701

Tobin, M. C., Drager, K. D. R., \& Richardson, L. F. (2014). A systematic review of social participation for adults with autism spectrum disorders: Support, social functioning, and quality of life. Research in Autism Spectrum Disorders, 8(3), 214-229. https://doi.org/10.1016/j.rasd.2013.12.002

Wang, S. (2020). Spatial patterns and social-economic influential factors of population aging: A global assessment from 1990 to 2010. Social Science \& Medicine, 253, 112963. https://doi.org/10.1016/j.socscimed.2020.112963

Weisberg, H., Krosnick, J. A., \& Bowen, B. D. (1996). An introduction to survey research, polling, and data analysis (3rd ed.). Sage. 